\title{
BIM AS AN ENABLER FOR DIGITAL TRANSFORMATION
}

\author{
James Heaton ${ }^{1}$, Ajith Kumar Parlikad ${ }^{1}$, David Owens ${ }^{2}$, Neil Pawsey ${ }^{3}$ \\ ${ }^{1}$ University of Cambridge, Department of Engineering, Institute of Manufacturing, Charles Babbage Road, Cambridge, UK \\ ${ }^{2}$ Costain Group, Costain House, Vanwall Business Park, Maidenhead, UK \\ ${ }^{3}$ Professional Construction Strategies Group (PCSG), Corinthian House, Lansdowne Road, Croydon, UK \\ * Corresponding author
}

\begin{abstract}
Organisations all over the world are increasingly becoming digitally enabled, including infrastructure providers and are looking to use this new found a digital way of working to transform the organisation into a more lean, efficient and productive organisation. Digital transformation is not exclusively about digital technology but the fact that technology, which is digital, will enable the organisation to create greater informed decisions around there current and future challenges, objectives and strategy. While many organisations are currently going through a digital transformation process, there are challenges in demonstrating the value of such a transformation process to the broader organisation. This is partly due to the fact that for digital transformation to be successful it must encompass all of the organisation, including traditional business processes and functions that are not prone to change. Furthermore, it can be witnessed that digital transformation is not purely a technical solution but is also an organisational cultural change, one that allows for an agile approach to working and one that acknowledges failure in a positive perspective.
\end{abstract}

A framework is proposed in this paper that utilises the BIM information management processes and adopts them into a digital transformation process. The framework aims to not look at BIM within individual lifecycle stages, but the full adoption of BIM between all the lifecycles stages. Furthermore, it will support the full organisational adoption of BIM within all organisational functions such as risk management, customer reengagement, fiscal management, resource management, ETC. finally, the framework will enable the culture to change requirements by providing a collaborative and transparent environment to digital transformation.

\section{Introduction}

Digital transformation in a board sense has been a hot topic for discussion, both within the academic literature and within industry participation. Digital transformation is seen as a key organisational strategy to support sustainable growth. This is especially important with asset centric organisations that are being asked to deliver greater operational performance within increasing financial constraints and limiting environmental resources. Furthermore, there is an increasing regulatory landscape in the remit of data and information management that aims to ensure transparency in public services, security and protection of data around personal records and security-related data and standardise data formats, models and structures. Many of these regulations are being enforced by legal requirements with harsh penalties. One such example is the General Data Protection Regulation (GDPR) that aims to protect the personnel records of customers that organisations hold and gives control to individuals to focus companies on deleting there records, failure to conform to this regulation can result in a 20 million euro fine or $4 \%$ of annual global turn over. (European Union 2016).

Fundamentally organisations are being asked to achieve more with a decreasing financial envelope, increasing data management regulations and with minimal impact on the natural environment. Hence the need for organisations to develop their digital transformation capabilities in line with the above challenges.
In recent years Building Information Modelling (BIM) has been a widely discussed topic, both within the academic literature and within industry applications. BIM is being seen by many organisations as a critical enabler to embed digital processes within their organisation. Specifically, the information management processes within BIM aids in breaking down the traditional information siloes and barriers that are present in asset centric organisations. BIM itself has been adopted within the silos of the organisations. In general BIM adoption has been widely successful within the design and construction phases, but with limited adoption within the operational and maintenance (O\&M) phases. Furthermore, BIM has mostly been adopted within individual departments such as the civil design, geotechnics and architectural design, but with limited adoption in organisation management functions such as risk management, financial management and health and safety management.

Asset Management has emerged as a domain both within academia and industry as a set of methodologies, framework and tools that support the alignment of organisational objectives around the value of their physical assets. Asset Management is gaining support in industry adoption by ISO 55000 that defines a methodology and associated processes need to develop an asset management system, from a management perspective point-of-view (ISO 2014). Asset management aims to align the organisational requirements, both financial and non-finance to the value of the operational performance of their physical assets that encompass your traditional asset-centric departments such as your operational 
and maintenance teams but also your management functions such as risk management and fiscal management. Due to the broad, collaborative and alignment nature of asset management, it is considered a critical element to a successful digital transformation process.

A recent survey found that $78 \%$ of organisations believe that digital transformation will become critical for their organisational profitability within the next two years. However, 63\% believe the transformation (both technical and management) is happening to slow. From the same survey, it was cited that a "lack of urgency" was a frequent obstacle and only $38 \%$ responding that the Digital Transformation was a permanent fixture on the CEO's agenda and forms part of the broader organisational vision and objectives (Fitzgerald et al. 2018). Furthermore, while most employees would agree with the vision, they are poorly equipped with the knowledge, information, tools and techniques to help them support the digital transformation process.

As can be seen within Fig 1, a recent study rated the construction industry (including asset management) as the least digitally mature sector. It can be clearly witnessed that digital transformation within the construction industry lacks in a clear and comprehensive strategy, required digital skills and knowledge, lacking support from leadership and more skills within the leadership team to support the digital transformation process.

Figure 1 Digital Maturity of Sectors (Kane, Gerald C and Palmer, Doug and Phillips, Anh Nguyen and Kiron, David and Buckley 2015)

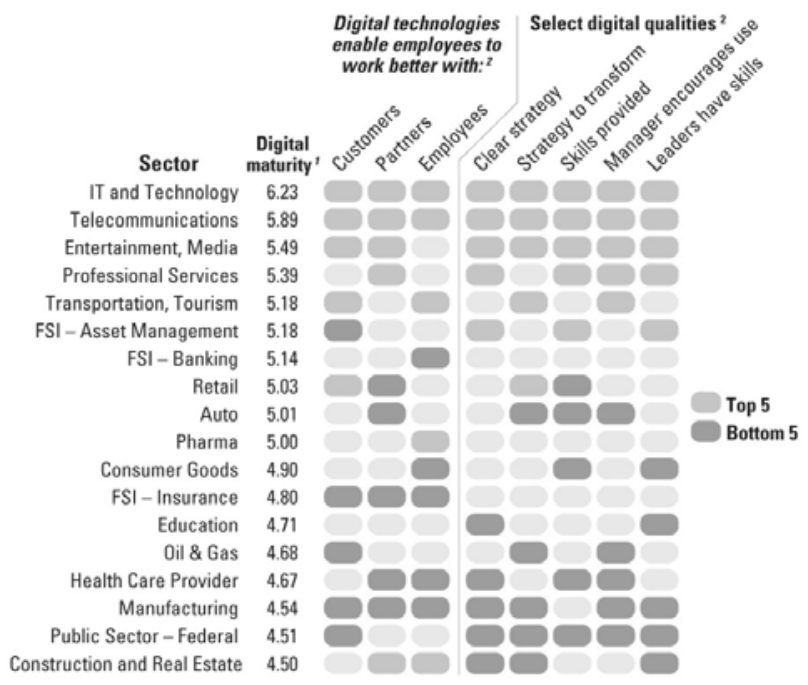

This paper investigates the use of BIM in the information management process within to support an asset-centric organisations journey throughout the digital transformation process. Section 2 provides an overview of current academic literature and standards within the domains of digital transformation, BIM and asset management. Section 3 proposes a digital transformation framework that is enabled by BIM. Finally, section 4 provides a conclusion and guidance on the need for future research requirements.

\section{Literature and standards review}

This section reviews the management domains of Digital Transformation and the more technical domains of BIM and asset management. While the scope of this paper is focused on organisations that manage infrastructure and estates, it is essential to go beyond these domains in order to investigate the best practice, as such the domains of finance, health care and marketing will be revised.

\subsection{Digital Transformation Strategies}

First, it should be noted that digital transformation strategies are not an Information Technology (IT) strategy. IT strategies focus on the IT hardware and software deployment with only a narrow understanding of the operational asset value that they support. Furthermore, IT strategies propose a roadmap for the future development and use of IT within the organisation, and it does not explicitly focus on the transformation of individual products, services or projects (Matt and Hess 2015).

Digital transformation is not a new concept. J.F. Rockart et al in 1979 noted the advancement of Information Management Systems (IMS) and how their use would revolutionize and transform the traditional business models, but Rockart witness that the emerging IMS where rarely successful and often did not cross organisational departments (Rockart 1979). Rockart et al noted the need for tools and techniques so organisations could develop holistic approaches to a digital approach that engaged all levels of management and all functions. J. c Henderson et al in 1993 noted that IT was evolving from its more administrative role to a more strategic role within an organisation and as such requires a strategic management process (Henderson and Venkatraman 1993). Furthermore, it was noted the emerging domain of strategic management of information technology and the need to align this emerging domain with existing management processes.

the emergence of IT evolving from an administrative task to strategic tool to exploited as a mean to controls risk and increase profitability, took the focus away from IT as a hardware / software solution and focused more of a digital approach, creating the emergence of digital strategies. (Drnevich and Croson 2013) notes the development of a "Digital Business Strategy" that provides a framework for the integration of IT and organisational strategy. While this demonstrates the evolution from administrating IT to digital strategy, it doesn't focus specifically on the transformation process itself, but rather on the current and future business opportunities based on digital technology and processes and not the transformation requirements to achieve these objectives.

There are an emerging set of definitions that aim to provide the scope and structure of what is specifically digital transformation. When reviewing the definitions, they generally fit into one of three categories as summarised below.

1. Technology - focused on the design, development and extension of IT hardware and software within an 
organisation, with little to no focused on the processes that the technology supports.

2. Processes - focused on the digitalisation of organisational processes with little to no bias on individual technology solutions.

3. Framework - focused on the development of the digital transformation processes and framework itself, with no bias to individual processes or technology.

Table 1 provides a summary of the most popular definitions within the literature along with their reference and category.

Table 1 Definitions of Digital Transformation

\begin{tabular}{|c|c|c|}
\hline definition & Category & Reference \\
\hline $\begin{array}{l}\text { Digital transformation } \\
\text { strategy is a blueprint that } \\
\text { supports companies in } \\
\text { governing the } \\
\text { transformations that arise } \\
\text { owing to the integration of } \\
\text { digital technologies, as } \\
\text { well as in their operations } \\
\text { after a transformation. }\end{array}$ & Framework & $\begin{array}{c}\text { (Matt and } \\
\text { Hess 2015) }\end{array}$ \\
\hline $\begin{array}{l}\text { Extended use of advanced } \\
\text { IT, such as analytics, } \\
\text { mobile computing, social } \\
\text { media, or smart embedded } \\
\text { devices, and the improved } \\
\text { use of traditional } \\
\text { technologies, such as } \\
\text { enterprise } \\
\text { planning (ERP), to enable } \\
\text { significant } \\
\text { improvements. }\end{array}$ & Technology & $\begin{array}{c}\text { (Chanias } \\
\text { 2017) }\end{array}$ \\
\hline $\begin{array}{l}\text { Digital transformation is } \\
\text { concerned with the changes } \\
\text { digital technologies can } \\
\text { bring about in a company's } \\
\text { business model, which } \\
\text { result in changed products } \\
\text { or organizational structures } \\
\text { or in the automation of } \\
\text { processes. These changes } \\
\text { can be observed in the } \\
\text { rising demand for Internet- } \\
\text { based media, which has led } \\
\text { to changes in entire } \\
\text { business models (for } \\
\text { example in the music } \\
\text { industry). }\end{array}$ & Processes & $\begin{array}{c}\text { (Boufenneche } \\
\text { et al. 2016) }\end{array}$ \\
\hline
\end{tabular}

While there is not a specific framework or methodology that is widely used within developing digital transformation strategies, there are some common themes that have been emerging from the digital strategy domain that include the use of technologies, structural changes, change in value creation and financial aspect, see figure 2 (Vial 2019).
Figure 2 Common Themes within Digital

Transformation (Matt and Hess 2015)

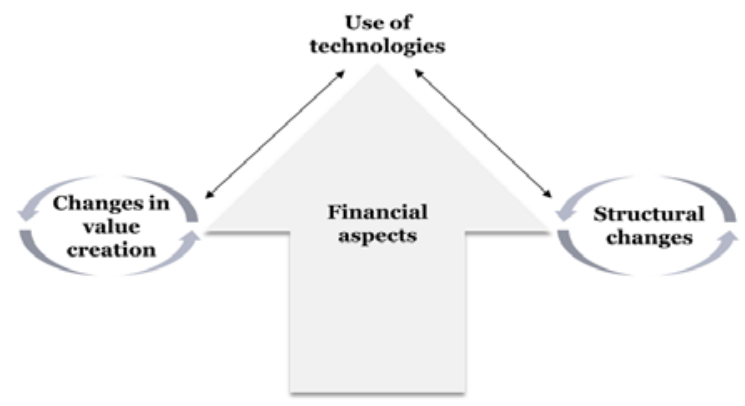

the key difference from a general digital / IT strategy to digital transformation is the creation or change in new value paths including financial and non-financial value. The digital transformation process is generally supported by disruption within traditional business models, changes in customers' expectations or a change in the regulatory landscape, which leads to a strategic response and hence the development of a digital transformation strategy to change or create the newly required value path.

\subsection{Building Information Modelling (BIM) as a strategic organisational tool for transformation}

As noted within Section 1, BIM has been widely adopted within the design and construction phases specifically by lead designers, contractors and the wider supply team. The adoption of BIM within the design and construction phase has demonstrated a reduction within total design and construction cost, increase in productivity and improved risk management processes (Azhar 2011; RIBA Enterprises 2017; Bryde, Broquetas, and Volm 2014). But the adoption of BIM within asset management is limited, despite the O\&M phase being over $80 \%$ of an asset's whole-life (Gao and Pishdad-Bozorgi 2019). Furthermore, the adoption of BIM within the broader organisational departments such as financial management, customer engagement, human resources and business development is limited (Kelly et al. 2013).

There is no direct evidence of BIM being used directly within a digital transformation process. While there are examples of BIM being used to aid the development of strategic frameworks. Bill Succar proposes a comprehensive framework for industry stakeholder engagement within BIM, an essential part of this framework is the tri-axel model, see figure 3. BIM fields look at identifying the stakeholders, BIM stages denote the maturity of the given stakeholder and BIM lenses provide the depth and effort needed to access the BIM fields / stages (Succar 2009). 
Figure 3 BIM Framework, stages, lenses and fields (Succar 2009)

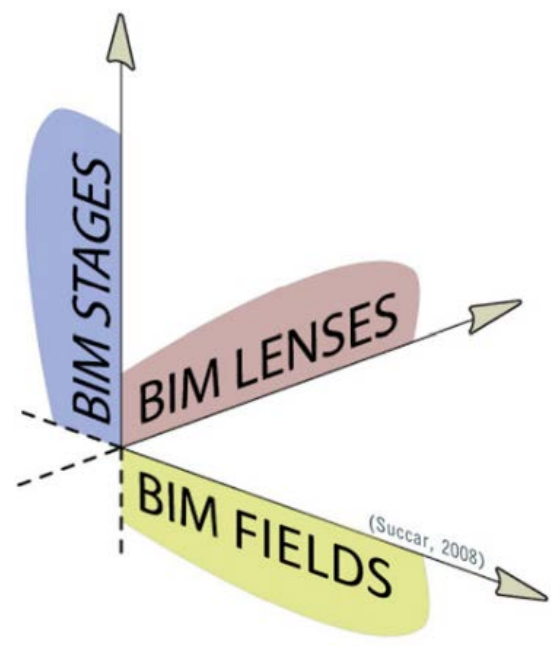

Furthermore, a recent development by the Centre for Digital Built Britain (CDBB) saw the development of a BIM Benefits Measurement Methodology (BMM) that provides a methodology for the measuring of benefits (Centre for Digital Built Britain 2018).

Despite the recent developments, it can still be witnessed that one of the biggest challenges within BIM is measuring its value (Waterhouse and Philp 2016), hence the lack of the adoption of BIM within the O\&M phase. Furthermore, BIM has been used as a tool for designers and contractors but has not been used as a transformative process within the organisation, despite the distinct advantages.

\subsection{Summary}

Much like in the 1980s when IT evolved from a administrative role into strategic and business development, business digital strategies are evolving into digital transformation strategies. This is being led by a wave of disruption within traditional business models, increasing customer demands and new competitive landscape that is forcing the need for a transformation in creating or changing value paths for the organisations, your traditional digital strategy does not support the value creation process.

While there have been some examples of asset management organisations using technology to transform elements of their organisation, they usually are in an ad-hoc manager and solely focused on the technology solution and not the organisational processes.

It can be seen that there is a clear need for a framework that enables BIM to be used as a tool to aid in the development of digital transformation processes.

\section{Framework Development}

the proposed framework utilises the elements of asset management, BIM and common themes within digital transformation strategy development, see figure 4 .
Figure 4 BIM enables Digital Transformation Framework

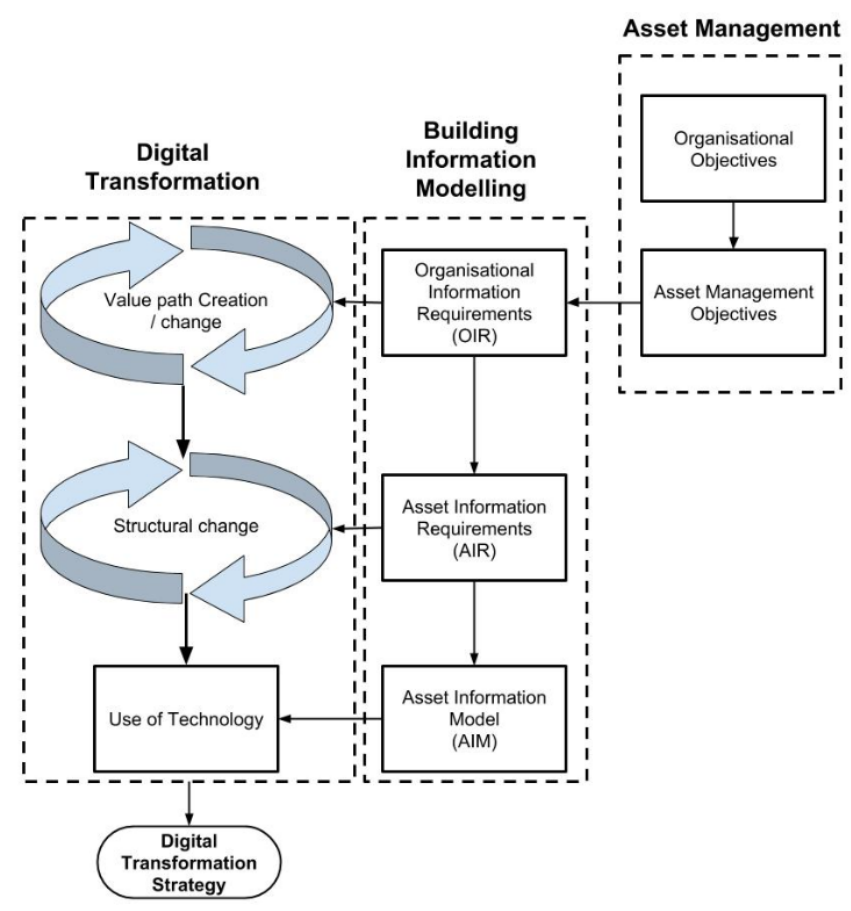

The above framework utilises the universal themes of digital transformation, information management processes within BIM and asset management. Each section of this framework is described in detail below.

\subsection{Organisational Information Requirements (OIR)}

On the left-hand side, we have the documents produced as part of designing and developing asset management systems. This includes the creation of asset management objectives that are directly derived from organisational objectives. The asset management objectives should be used to develop a set of OIR's. The OIR's are a set of questions that when answers will confirm (or not) if the organisation are meeting their objectives. As an example, if the organisation had an objective to reduce the operational cost by $5 \%$, they will want to ask such questions as, how much is my total operational cost? What are the assets systems that cost me the most? What is the minimum required operational performance? And who is the principal sponsor of achieving this objective?

From a digital transformation perspective, the value path creation / change comes from the need for the organisation to transform itself, typically from external factors such as changing business models, changing expectations of customers and a new emerging competitive landscape. These challenges / disruptions are documented. Much like the asset management objectives and used to develop OIR's

Value path creation OIR's generally takes the form of two kinds. Firstly, information that provides feedback on the value currently being created, to validate that it is still meeting a customer / commercial need. Such an example would be collection customer feedback from a new feature on an application or a review of the overcrowding risk on a railway 
line by reviewing the movement of people on and off the train. Secondly, information that validates that a new value path is needed or an existing one needs to change to meet the new requirements. As an example, collecting information regarding the demand for new railway service, or the need for a new ticketing model. this information can be received by customer surveys as feedback for small initial trials.

In general, the OIR's for the value creation is more abstract in nature than the asset management objectives, this is due to their board nature and context.

\subsection{Asset Information Requirements (AIR)}

This sections aims to translate the OIR's into AIR's. The AIR's should aim to answer the questions developed from the OIR. The information captured at this level should be captured at an asset system level (see figure 5 for the classification of an asset, with examples from UNIClass (Delany 2015)) and capture all of the required information to ensure that organisation can make an informed decision around the given objective.

Figure 5 Asset Classification System

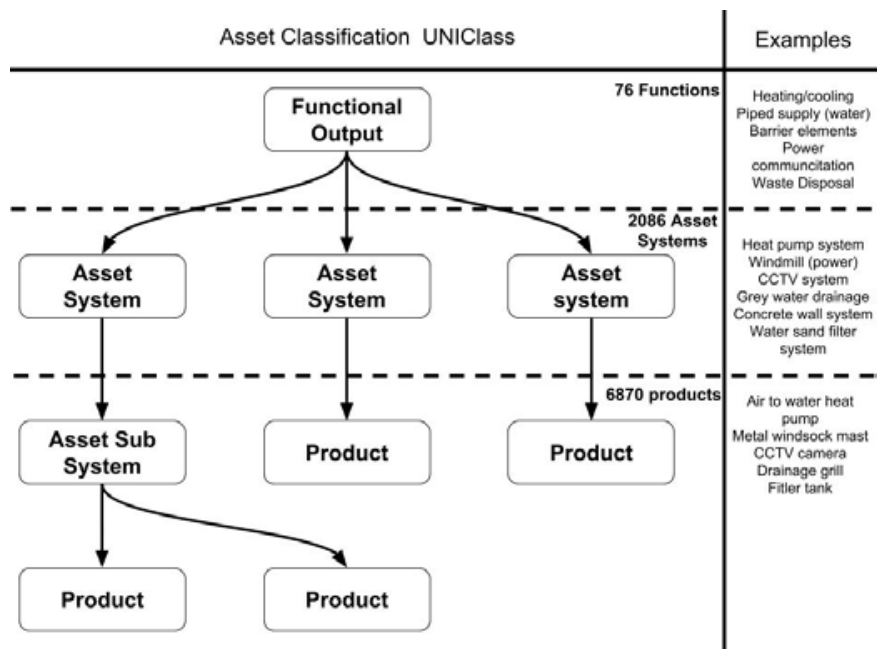

Structure change references to the organisational processes that need to change to support and develop the new value paths. This includes but not limited to change in organisational scope due to a new market segment, the need for new digital skill sets, change to organisational structure, e.g. consolidating departments and a changing regulatory landscape. Within this context, the AIR should support the organisational structure change requirements.

Much like the OIR the AIR take generally two forms. First, it is to capture the required information needed to support the structural change. As an example, this could state the required level of digital capability within a given section of the organisation or required level of integration between departments to support a new value path. Secondly, it is validating that the required organisational change has taken place. This is achieved by witnessing and documenting the change within the AIR. As an example, you could measure on a monthly bases the increase in digitally skilled employees and validate if you are (or not) meeting your structural change requirement.

\subsection{Asset Information Model (AIM)}

Finally, is the development of an AIM. The AIM acts as a central repository for all asset related information, this AIM should integrate with all the organisational departments including financial, customer and risk, not just operational and maintenance. If the AIM is developed by the OIR and AIR processes outlined above, it will support the direct line-of-sight from asset performance to organisational / asset management objectives.

From a digital transformation perspective, the AIM acts as an integration between the information requirements developed during the value path creation and the structural change with the adoption of new technology. The AIM can provide the requirements for the new use of technology, both from a technical point-of-view and a managerial point-of-view.

\section{Conclusion}

This paper proposes how the current information requirements development framework within the BIM standards can help to support the development of a digital transformation strategy within an asset management organisation.

The paper starts by reviewing the current literature in the domain of digital transformation. Where it is noted that IT has moved from an administrative role in the 1980s into a strategic organisational role. Digital strategies started to appear within the early $21^{\text {st }}$ century and more recently digital transformation strategies have appeared to combat ever-evolving disruptions that are challenging traditional business models, increasing customer demands and a fast-moving competitive landscape.

BIM has been cited within the asset management industry as a key enabler to support an increase in productivity while limiting risk and gaining better control over quality management processes. But despite this, BIM adoption within asset management and the O\&M lifecycle phase is limited. Furthermore, while BIM would be indirectly helping asset management organisations to adopted digital processes, there is no formal methodology or framework that aligns BIM, asset management and the common principles of digital transformation.

This paper proposed a framework for the development of a digital transformation strategy that is enabled by BIM and supported by asset management. The information requirements relationships as defined within PAS 1192-3 (British Standards Institute 2014) are used to bridge the gap between digital transformation concepts and BIM.

Future research should look at that this initial research effort and investigate how common BIM documentation and strategic organisational documentation can support each other within developing the framework into an industrial case study.

\section{References}

Azhar, Salman. 2011. "Building Information Modeling (BIM): Trends, Benefits, Risks, and Challenges for the AEC Industry." 
Leadership and Management in Engineering 11 (3): 241-52. doi:10.1061/(ASCE)LM.1943-5630.0000127.

Boufenneche, L, M Chouki, S Khedimallah, H Belila, D Sekki, and A Boudouda B Nekhoul. 2016. "Options for Formulating a Digital Transformation Strategy" 2016 (June): 17-33. doi:10.1108/10878571211209314.

British Standards Institute. 2014. PAS 1192-3:2014 Specification for Information Management for the Operational Phase of Assets Using Building Information Modelling. British Standards Institute. https://bim-level2.org/en/standards/.

Bryde, David, Martí Broquetas, and Jürgen Marc Volm. 2014. "The Project Benefits of Building Information Modelling (BIM)." International Journal of Project 31 (June 2011): 97180. doi:10.1016/j.ijproman.2012.12.001.

Centre for Digital Built Britain. 2018. "BIM Benefits Methodology and Report." https://www.cdbb.cam.ac.uk/BIMLevels/BBM.

Chanias, Simon. 2017. Association for Information Systems AIS Electronic Library (AISeL) MASTERING DIGITAL TRANSFORMATION: THE PATH OF A FINANCIAL SERVICES PROVIDER TOWARDS A DIGITAL TRANSFORMATION STRATEGY. http://aisel.aisnet.org/ecis2017_rp.

Delany, Sarah. 2015. "UNICLASS Calssification." NBS. https://toolkit.thenbs.com/articles/classification.

Drnevich, Paul L, and David C Croson. 2013. "INFORMATION TECHNOLOGY AND BUSINESS-L EVEL STRATEGY: TOWARD AN INTEGRATED HEORETICAL PERSPECTIVE" 37 (2): 483-509.

European Union. 2016. "Regulation 2016/679." Official Journal of the European Communities 2014 (March 2014): 188. doi:http://eurlex.europa.eu/pri/en/oj/dat/2003/1_285/1_28520031101en0033 0037.pdf.

Fitzgerald, By Michael, Nina Kruschwitz, Didier Bonnet, and Michael Welch. 2018. "Embracing Digital Technology A New Strategic Imperative."

Gao, Xinghua, and Pardis Pishdad-Bozorgi. 2019. "BIMEnabled Facilities Operation and Maintenance: A Review." Advanced Engineering Informatics 39 (August 2018): 227-47. doi:10.1016/j.aei.2019.01.005.

Henderson, John c, and N Venkatraman. 1993. "Strategic Alignment: Leveraging Information Technology for Transforming Organizations." IBM Systems Journal 38: 47284.

ISO. 2014. "BS ISO 55000 Series - Asset Management." doi:10.1177/0032329211420047.

Kane, Gerald C and Palmer, Doug and Phillips, Anh Nguyen and Kiron, David and Buckley, Natasha. 2015. "Strategy, Not Technology, Drives Digital Transformation." MIT Sloan Management Review and Deloitte University Press 14: 1-25.

Kelly, Graham, Michael Serginson, Steve Lockley, Nashwan Dawood, and Mohamad Kassem. 2013. "BIM for Facility Management: A Review and a Case Study Investigating the Value and Challenges." 13th International Conference Applications of Virtual Reality, no. October: 30-31. http://itc.scix.net/data/works/att/convr-2013-20.pdf.
Matt, Christian, and Thomas Hess. 2015. "Digital Transformation Strategies" 14 (September). doi:10.1007/s12599-015-0401-5.

RIBA Enterprises. 2017. "National BIM Report,” no. 5: 1-28. doi:10.1017/CBO9781107415324.004.

Rockart, J. F. 1979. "Chief Executives Define Their Own Data Needs." Harvard Business Review 57 (2): 81-93. https://hbr.org/1979/03/chief-executives-define-their-owndata-needs.

Succar, Bilal. 2009. "Building Information Modelling Framework: A Research and Delivery Foundation for Industry Stakeholders." Automation in Construction 18 (3). Elsevier B.V.: 357-75. doi:10.1016/j.autcon.2008.10.003.

Vial, Gregory. 2019. "Understanding Digital Transformation : A Review and a Research Agenda." Journal of Strategic Information Systems, no. xxxx. Elsevier: 0-1. doi:10.1016/j.jsis.2019.01.003.

Waterhouse, Richard, and David Philp. 2016. "National BIM Report." National BIM Library, 1-28. doi:10.1017/CBO9781107415324.004. 